\title{
A Descriptive Study Identifying Gaps in the Effective Implementation of Mercury-containing Device Phase-out in Selected DOH-retained Hospitals
}

\author{
Zenith DLT Zordilla \\ Institute of Health Policy and Development Studies, National Institutes of Health, University of the Philippines Manila
}

\begin{abstract}
Background and Objective. After the 2008 phase-out of mercury-containing medical devices, the implementation status was evaluated by this study to know the program effectiveness in removing mercury exposure risks in health facilities.

Methods. A cross-sectional survey was done to determine the amount of mercury stored in ten selected Department of Health ( $\mathrm{DOH}$ )-retained hospitals. Key informant interviews were also performed with Pollution Control Officers to determine their program implementation status, strengths, and areas for improvement.

Results and Discussion. All hospitals initiated the mercury minimization program but none has fully implemented it. The total amount recorded is $213.5 \mathrm{~kg}$ for mercury-containing materials. A discrepancy of $31.4 \%$ exists compared to the initial 2008 inventory of $312.7 \mathrm{~kg}$. The main strength identified by the key informants was the one-time collection of mercury devices in hospitals. Hospitals need administrative and logistic support to properly implement mercury phase-out, particularly on monitoring of temporary storage. Disposal protocols should also be created to fully eliminate mercury exposure in the hospitals.
\end{abstract}

\section{INTRODUCTION}

Elemental and methylmercury is highly toxic to human health. ${ }^{1}$ Mercury is classified as a persistent, bioaccumulative toxin and the continued mercury presence in various products will result to continued risk of exposure. ${ }^{2}$ Various studies have already established the human health impact of mercury in the environment threats. ${ }^{3,4}$ Transplacental exposure may result in mental retardation, constriction of the visual field, hearing loss, language disorders, and memory loss. ${ }^{1}$ Inhalation of mercury vapor can produce permanent and harmful effects on the digestive, immune, respiratory, and renal systems.

The World Health Organization (WHO) identified the health care sector as one of the major contributors to the global anthropogenic releases of mercury. ${ }^{5} \mathrm{WHO}$ proposed national assessments that will lead to a ban of mercurycontaining health care devices, and the eventual sound management of healthcare mercury wastes. ${ }^{6}$ Similarly, the Philippines through its Department of Environment and

Corresponding author: Zenith DLT Zordilla, MD Institute of Health Policy and Development Studies National Institutes of Health University of the Philippines Manila 623 Pedro Gil Street, Ermita, Manila 1000, Philippines Telefax: +6323543832

E-mail: zzordilla@gmail.com Natural Resources (DENR) issued a technical document to guide a national mercury assessment using a United Nations Environment Programme (UNEP) Toolkit last 2008. ${ }^{6}$ Among the categories of mercury $(\mathrm{Hg})$ emissions identified were breakage of thermometers, sphygmomanometers, and other mercury-containing health care instruments. These 
instruments were identified to constitute 20 percent of $\mathrm{Hg}$ releases in the environment, translating to $46,653 \mathrm{~kg} \mathrm{Hg}$ emissions per year. ${ }^{6}$

The Philippines showed its commitment in reducing harm from healthcare wastes through various initiatives, aside from using UNEP's toolkit in 2008. DENR and the Department of Health (DOH) issued Joint Administrative Order 2005-002, entitled "Policies and Guidelines on Effective and Proper Handling, Collection, Transport, Treatment, Storage, and Disposal of Health Care Wastes." The said guideline outlines management options for biological and hazardous wastes, including mercury-containing wastes, generated from health care facilities. DENR is mandated as the primary agency for implementing rules and regulations on healthcare waste management, while $\mathrm{DOH}$ functions to evaluate hospitals' compliance for proper health care waste management program. ${ }^{7}$

In 2008, DOH issued Administrative Order (AO) 2008-21, Gradual Phase-out of Mercury in all Philippine Health Care Facilities and Institutions, as a means to phaseout mercury-containing devices in healthcare facilities. ${ }^{8}$ AO 2008-21 outlines a Mercury Minimization Program (MMP) and a clean-up protocol for mercury spills in healthcare facilities. ${ }^{8}$ However, in spite of the initial two-year implementation of the mercury phase-out program, it has failed in lessening the risk of exposures of the public from mercury due to its continued presence in hospitals. This study, therefore, aimed to provide insights as to the implementation of the phase-out of mercury-containing medical devices (e. g. body temperature thermometer, sphygmomanometer, and dental amalgam) based on the provisions set by $\mathrm{DOH} \mathrm{AO}$ 2008-21. Specifically, this study (1) determined the amount of mercury stored in 10 selected DOH-retained hospitals in the National Capital Region (NCR); (2) described the current status of implementation of the phase-out and compared it to the provisions set by DOH AO 2008-21; (3) determined factors (conceptual, organizational, knowledge-based, technical, and economic) affecting the proper implementation of DOH AO 2008-21; and finally, (4) documented and described various gaps and recommended solutions as identified by respondents for the eventual phase-out of mercury-containing devices in hospitals in the Philippines.

\section{METHODS}

\section{Ethical Review}

This study was reviewed and approved by the University of the Philippines Manila Research Ethics Board prior to implementation.

\section{Study Design, Study Population and Setting, and Sampling Design}

This cross-sectional study determined the amount of mercury (in kilograms) stored in mercury-containing devices in DOH-retained hospitals in the National Capital Region
(NCR). Aside from selecting DOH-retained hospitals, bed capacity was identified as another criterion for the study. Larger hospitals will generally have an increased load of mercury-containing devices and, therefore, are more probable to have encountered problems in implementing AO 2008-21.

Once hospitals which meet the criteria were identified, key informant interviews with a representative of a Mercury Management Team were conducted.

\section{Study Procedures}

An endorsement from $\mathrm{DOH}$ was sought to conduct the study in hospitals. Selected hospitals were informed of the study by sending letters of invitation indicating the week of the intended hospital visit. The actual dates of the visit were unannounced in order to minimize a Hawthorne effect. During the actual visit, the principal investigator was accompanied by the hospital director's representatives to the offices of the interviewees: usually the Pollution Control Officer (PCO), Mercury Management Team Leader, or the Health Care Waste Management Team Leader. The study was explained to the interviewees and their consent sought, as signified by affixing their signatures in an informed consent document.

Key informants were assigned a letter (Hospital A - J) that corresponded to the chronological order of the interviews. The letter was written on the interview forms' upper right hand corner to anonymize the documents. Semi-structured interviews were performed with the various representatives of the Mercury Management Team of the selected hospitals. Audio recordings of the interview were transcribed and sent to each interviewee for validation.

Direct observation of the temporary mercury storage area by the principal investigator was performed; investigator was accompanied by the key informant. In addition, secondary data were accessed by reviewing records and labels in the hospitals, as well as in the DOH Central Office, to quantify the amount of stored mercury for a particular hospital. This meant that in lieu of actual counting of mercurycontaining devices, a review of records at each hospital and at the Central Office was performed. Finally, a checklist for reviewing the implementation of the DOH AO 2008-21 guidelines was used to evaluate the MMP.

\section{Plan of Analysis}

Data collected from the key informant interviews were tabulated. Thematic analysis was used to assess the data using the following: 1) presence/absence of certain practices, or deviations of the phase-out of mercury containing devices from the DOH AO 2008-21 guidelines; 2) perceived factors affecting the success/failure of implementation of the mercury phase-out in hospitals using the classification by Burgos-Hernandez, namely: a) organizational, b) knowledgebased, c) technical, and d) economic; and 3) discussion of the gaps and solutions identified by the stakeholders. 
Proposed solutions were weighed in terms of their a) benefit to the population, b) fairness in resource allocation, c) cost and d) administrative feasibility.

\section{Limitations of the Study}

This study is limited to mercury thermometers, sphygmomanometers, and dental amalgam. However, mercury in health care is not limited to these aforementioned items. Due to the limited sample size, the applicability of the results cannot be generalized for all hospitals.

\section{RESULTS}

\section{Survey Results}

There was a total of $213.5 \mathrm{~kg}$ for mercury-containing materials (Table 1) sampled from a total of 10 hospitals. A change of $31.4 \%$ is noted when compared to the inventory in 2010; an overall total of $312.7 \mathrm{~kg}$ was recorded for the same hospitals. Six out of 10 hospitals sent representatives to the series of $\mathrm{DOH}$ seminars on mercury management in 2011. There was another DOH seminar specific for mercuryfree Dentistry that was attended by government dentists and nurses in 2013. Only two out of the ten sampled hospitals regularly conduct hospital-wide information campaigns regarding mercury management.

\section{Economic factors affecting mercury minimization programs (MMPs)}

Four informants said there was adequate support from their own hospitals. Three did not comment. Two out of 10 key informants noted a lack of financial support to the MMP. One of them proposed a Temporary Mercury Storage Area in 2012 following a specification stated in the AO 21, which required a budget of $\mathrm{PhP} 212,000.00$. However, the project did not push through due to lack of funding. This initial cost would have been more economical when considering a case which happened in one hospital in 2013. In 2013, a mercury spill incident happened in one hospital, which was managed by a DOH-Environmental and Occupational Health Office team and the Health Emergency Management Staff (HEMS) by disbursing a total of PhP1,000,000.00 to cover costs of clean-up and transport. The cost of cleanup, therefore, was at least 4 times the amount requested for proper storage. However, this did not include the cost of blood and urine mercury determinations performed for the affected employees, expenses related to the evacuation of informal settlers living adjacent to the hospital where the spill incident occurred, and other miscellaneous expenses.

\section{Organizational factors affecting mercury minimization programs (MMPs)}

Nine KIs stated that the AO 21-2008 was adopted by their hospitals in toto to serve as their guiding policy for purchasing alternatives to mercury-containing devices, and for collecting, retrieving, and storing mercury-containing devices. It is interesting to note that two hospitals developed their own mercury-free policies prior to the issuance of AO 21-2008. However, upon closer inspection of the provided document by one of the hospitals, it was a general "Environment Plan", and not necessarily a specific MMP. Hospitals that no longer store mercury consequently have no existing policies concerning mercury.

Emergency spillage plans were present in seven out of 10 hospitals, most of which were incorporated into their HEMS protocols. However, these plans were only applicable for minor spills. Larger scale spills require coordination with the Bureau of Fire Protection (BFP) and DOH-Central Office for management. Unfortunately, no records were shown by hospitals as to how these largescale mercury spillage plans were incorporated in hospital management systems.

In spite of such gaps, there was a relatively high adherence among hospitals in terms of organizational support to MMPs.

\section{Technical factors affecting mercury minimization programs (MMPs)}

Most hospitals performed a one-time collection of mercury-containing devices such as thermometers and sphygmomanometers, thus, an urgent need for managing a collection station for future mercury-containing devices. None of the storage areas had spill kits on-site except one

Table 1. Amount of stored mercury (in kg) In 10 DOH-retained hospitals during the initial survey and this current study

\begin{tabular}{cccccl} 
Hospital & Bed Capacity & $\begin{array}{c}\text { No. of } \\
\text { employees }\end{array}$ & $\begin{array}{c}\text { Mercury (kg) } \\
\text { initial survey 2010 }\end{array}$ & $\begin{array}{c}\text { Mercury } \\
\text { (kg) }\end{array}$ & Notes \\
A & 4,500 & 1,600 & 15 & 0 & No documentation available \\
B & 2,000 & 600 & 21.5 & 21.5 & No change \\
C & 700 & 900 & 5.5 & Spilled 6 bottles x 1/4 lb = approx. 2 kg.; no documentation available \\
D & 700 & 920 & 43 & 43 & No change; with label \\
E & 600 & 1,000 & 24 & 0 & Stolen; no documentation available \\
F & 500 & 762 & 33.5 & 33.5 & No change; with label \\
G & 500 & 524 & 3.0 & 1.95 & With label; no documentation available \\
H & 400 & 1,000 & 57.5 & 0 & No documentation available \\
I & 283 & 1,300 & 104.5 & 104.5 & No documentation available \\
J & 250 & 575 & 3.2 & 3.2 & No documentation available \\
\hline Total amount of mercury per device & 312.7 & 213.5 & - \\
\hline
\end{tabular}


storage area which was located inside one key informant's office (Figure 1) for close supervision. Additionally, all hospitals no longer procured and used dental amalgams. None of the hospitals performed sink trap cleaning. Five out of ten hospitals had tightly sealed plastic containers as storage units (Figures 2, 3, and 4). One of the hospitals used carton boxes wrapped with packaging tape (Figures 5A and $5 \mathrm{~B}$ ).

One hospital allowed the principal investigator to open their storage boxes for visual inspection. Other hospitals did not allow their storage containers to be opened due to fears of releasing mercury vapors, while one hospital instead showed a photo documentation of how mercury-

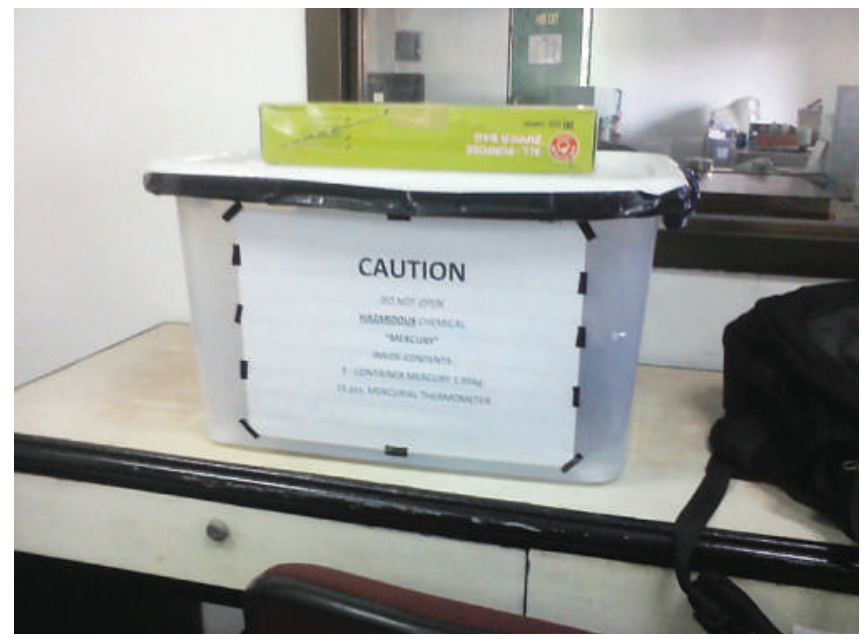

Figure 1. Stored mercury inside plastic container stationed in the Key Informant's air-conditioned office.

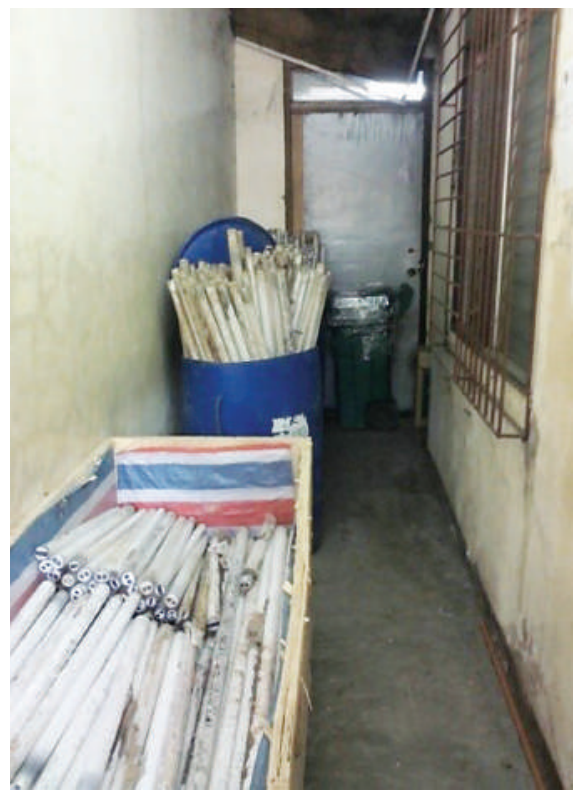

Figure 2. Stored mercury inside a durable plastic garbage container (green) with cling wrap and no labels. containing devices were packed and stored in 2008. Only two storage containers from the total observed containers had clear labels.

None of the hospitals had a mercury vapor sniffer to check for ambient air mercury levels. Two hospitals had a permanent record of condemned mercury thermometers, sphygmomanometers, and dental amalgams during a one-time collection done in 2008. The rest were unable to show their logbooks or permanent records. Three hospitals did not have clear delineations of fencing posts or walls in their designated storage areas (Figure 6). One of the three hospitals mixed the mercury storage container with other equipment such as unused paint and other construction materials (Figures 7Aand 7B). Another hospital converted an area formerly used for storing mercury-containing devices into a storage area for condemned mattresses and metal bed frames (Figure 8).

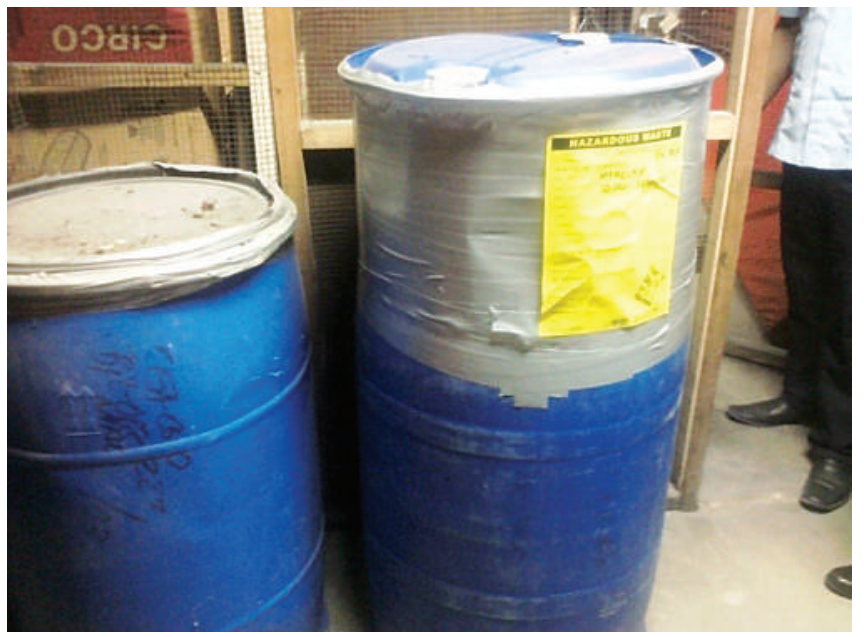

Figure 3. Stored mercury inside durable plastic water container with packaging tape. Clear label found.

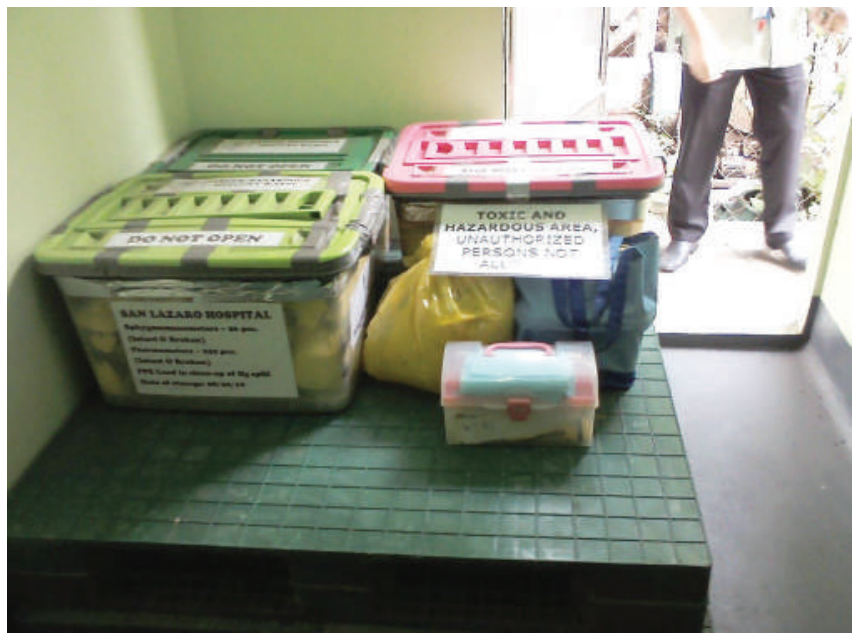

Figure 4. Stored mercury inside durable plastic container with packaging tape. Clear label found. 

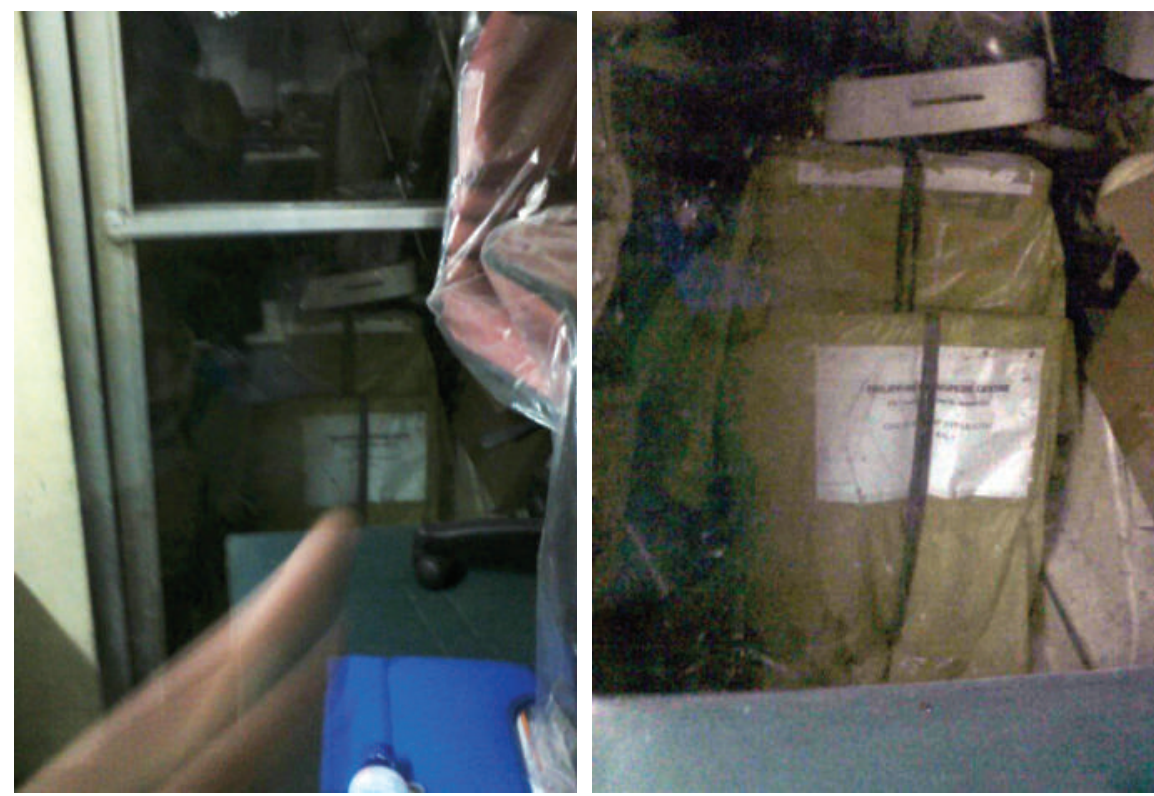

Figure 5A and 5B. Stored mercury inside paper box with packaging tape. Labels found.
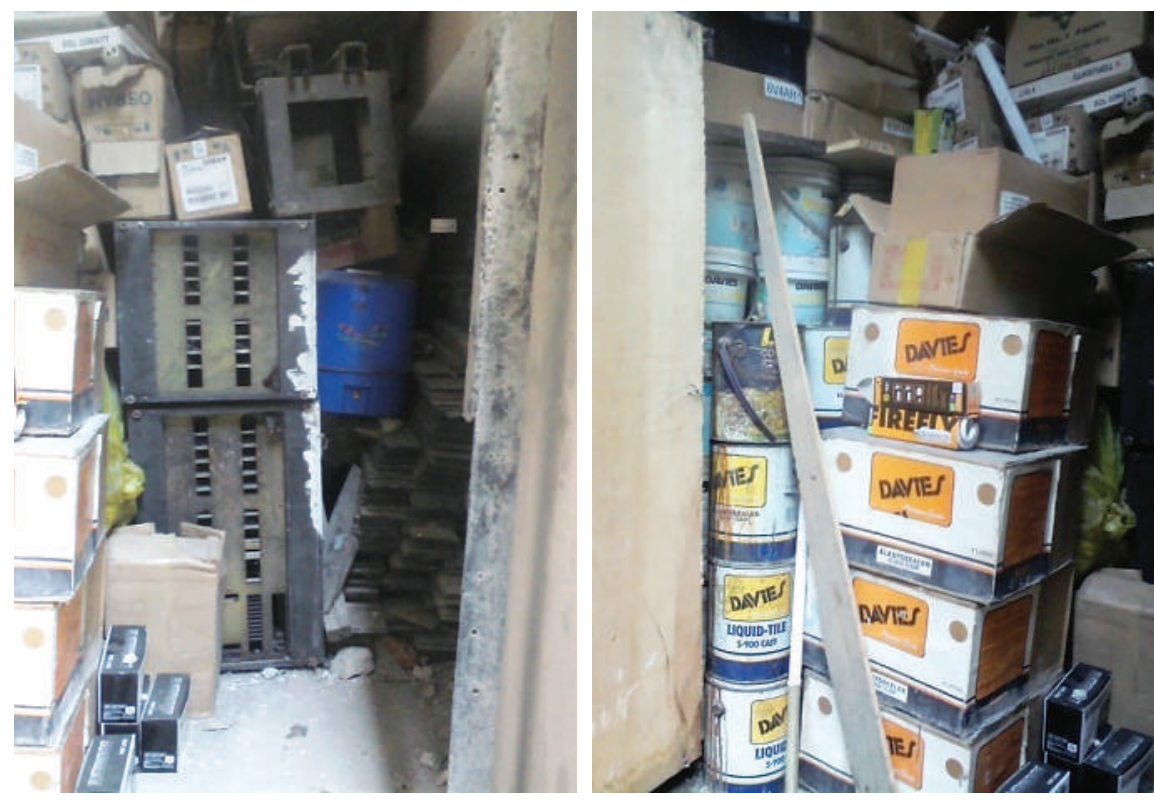

Figure 7A and 7B. Mercury storage area in old plastic water container (blue) located in a fenced storage area between two buildings mixed with other equipment such as paint.

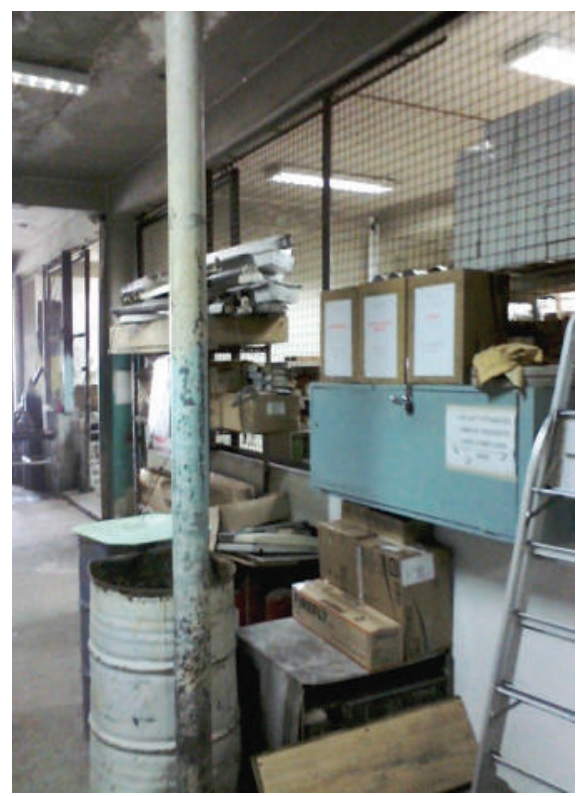

Figure 6. Mercury lamp storage area located in roofed corridor.

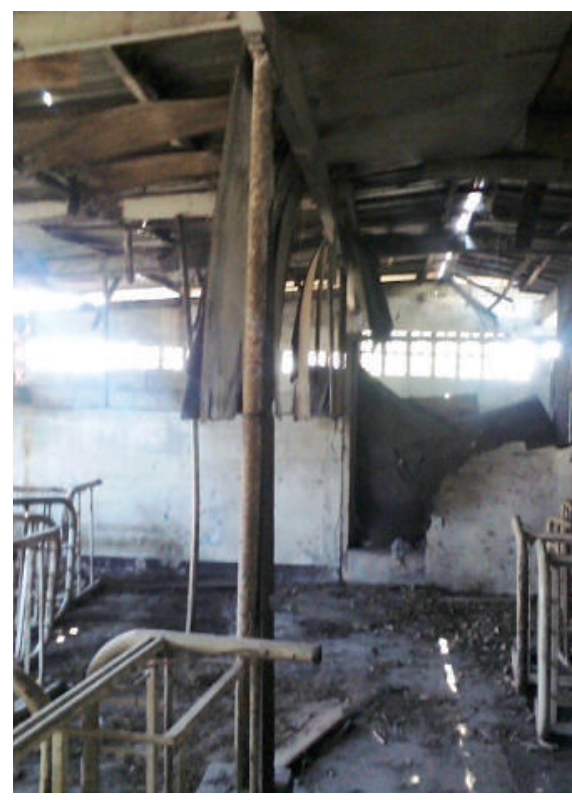

Figure 8. Former mercury storage area with leaking roof and adequate ventilation.
It may be gleaned from the data that technical specifications requiring hospitals to acquire materials not regularly procured such as mercury vapor sniffer, bund walls, and sink traps were not followed. In the case of areas where storage areas should have walls and fences, procurement plans were underway to include such needs under the health care waste management budget. Another missing technical specification from AO 21-2008 which need to be addressed was record keeping practices.

\section{Facilitating factors affecting mercury minimization programs (MMPs)}

One KI said that as a hospital with a low-resource setting, improvisation is a key adaptation factor. Instead of procuring high-end storage containers, Hospital I bought a large garbage container with cling wrap to convert it into a spill-proof storage container. They also converted one of the old storage areas with adequate roofing and walls as their mercury storage area. As stated by the KI, "Alam naming para 
sa ikabubuti natin itong phase-out, pero limited ang funds, kaya hanap kami ng paraan - nag-iimprovise kami" (We know that this phase-out program is for our good, but funds are limited so we need to find ways-we improvise).

Hospital E, to help ease the questions of physicians and nurses on the effectiveness of the mercury-free measuring devices, performed an in-hospital study comparing mercury-containing and mercury-free thermometer and sphygmomanometer. One of their criteria was that there should be a minimum variance of $+/-0.5$ degrees Centigrade $\left(\mathrm{C}^{0}\right)$ for thermometers and $+/-5 \mathrm{~mm} \mathrm{Hg}$ for sphygmomanometer. For Hospital B, a clear purchasing policy gave the Mercury Management Team definite legal framework to procure mercury-free devices. Hospital G procured digital alternatives, but encountered problems regarding deviations in the readings. This prompted Hospital $\mathrm{G}$ personnel to investigate the problem and found out that keeping the batteries fully charged minimized noted errors in the readings. Hospital D implemented regular maintenance services, which was part of the contract signed with mercuryfree device providers during the procurement process.

One key informant (Hospital C) identified that the one-time collection they performed to store all the mercurial devices, instead of a gradual phase-out, was a highly effective strategy for MMP.

\section{Inhibiting factors affecting mercury minimization programs (MMPs)}

Several obstacles were noted by the KIs in the Mercury Phase-out Implementation. Lack of funding and logistic support were also cited. The issue of final storage has always been a persistent question. Security of the storage units was also a problem. Inaccuracy and calibration problems were identified by three hospitals, especially during the first year of implementation. Acceptance of the medical staff was also raised, especially in two hospitals who implemented mercury phase-out programs prior to AO 21-2008. One KI stated that there were no standard operating procedures (SOPs) in case a mercury spill occurs.

\section{DISCUSSION}

Three main themes are identified to increase effectiveness of the current phase-out program: 1) Improve the technical knowledge of the main implementers with regard to the guidelines of Administrative Order 2008-21; 2) Provide administrative and logistic support to hospitals; and 3) Implement final disposal of mercury wastes stored in hospitals.

\section{Improving Technical Knowledge}

Mercury phase-out is still on-going and all technical guidelines are still in effect. Collection stations may no longer be appropriate for hospitals who have replaced all their mercury devices. An updated set of guidelines may be needed to expand the products covered by the phase-out.
An important gap noted in the phase-out is the lack of a centralized and standardized inventory in hospitals. Permanent records of mercury stores, Materials Safety Data Sheets (MSDS), and clear labels are lacking in most hospitals. Knowing the exact amount of mercury in mercurycontaining device is crucial information for developing a transport-storage-disposal (TSD) facility large enough to accommodate said wastes for long-term or final storage. Such inventories would also aid in providing metrics to determine whether the ultimate goal of the mercury phase-out and preventing exposures has been achieved or not. Should DOH opt to use the salt mines abroad, high monetary requirements are expected. A direct association of costs exists for the amount of mercury (and other hazardous material) wastes to be disposed of abroad. It must also be recognized that even with a phase-out in effect, it may take decades before all the mercury in use in various devices may be collected and removed. ${ }^{9}$ Thus, regular monitoring is important to make adjustments for possible storage areas. This also raises security concerns due to a possible diversion of stored mercury wastes from healthcare utilities into small-scale mining industries.

Among the facilitating factors recognized by KIs were: 1) commitment of Mercury Management Teams; 2) onetime collection for thermometer, sphygmomanometers, and dental amalgam; and 3) conduct of studies demonstrating acceptability of use for non-mercury devices. Similar results were seen when Health Care Without Harm (2010) presented their "Hospital Best Practices in Phasingout Mercury in Healthcare Facilities," which noted the following: 1) formation of an evaluation committee for $\mathrm{Hg}$ alternatives/ conduct of financial and technical evaluation of alternatives; 2) setting up of temporary storage inside the hospital; 3) engaging nurses as advocates for phase-out; and 4) distribution of mercury thermometers and spill kits (from a private hospital). ${ }^{11}$

UNEP recognizes that institutionalizing mercury-free alternatives as one important step to prevent generation of wastes containing mercury. ${ }^{12} \mathrm{DOH}$ and hospitals must work together to continue researches for mercury-free alternatives particularly on their cost-effectiveness and accuracy. Capacity-building programs should also be in place to cultivate commitment from implementers of the mercury phase-out.

\section{Providing Administrative and Logistic Support}

All other guidelines pertaining to setting up a storage area have variable levels of adherence due to costs. Applicable strategies for the Philippines can be adopted from Burgos-Hernandez which identify driving forces and areas of action as used in mercury elimination programs of Mexico (see Table 2). ${ }^{12}$ While most hospitals incorporated emergency spill plans in their HEMS protocols, records were unavailable during the time of visits for review and evaluation to determine what particular strategies recommended by Burgos-Hernandez can be applied. 
Table 2. Driving forces and areas of opportunity in mercury elimination per administrative stage (Burgos-Hernandez, 2009)

\begin{tabular}{|c|c|c|}
\hline Stage of the Administrative System & Strengths & Opportunity Areas \\
\hline \multirow[t]{4}{*}{ Acquisition } & Bidding process & price is the leading factor for provider selection \\
\hline & Centralized system & lack of budget \\
\hline & $\begin{array}{l}\text { technical specification of the products are } \\
\text { decided in a team process }\end{array}$ & $\begin{array}{l}\text { lack of internalization of hazardous waste management } \\
\text { cost, social and environmental costs }\end{array}$ \\
\hline & & $\begin{array}{l}\text { lack of environmental criteria for supplier selection } \\
\text { lack of knowledge on mercury elimination issue }\end{array}$ \\
\hline \multirow[t]{2}{*}{ Main storage } & safe storage & lack of control of broken thermometers \\
\hline & & lack of knowledge on mercury elimination issue \\
\hline \multirow[t]{2}{*}{ Secondary storage } & safe storage and formal maximum stock & lack of control of broken thermometers \\
\hline & available every 48 hrs & lack of knowledge on mercury elimination issue \\
\hline inventory & $\begin{array}{l}\text { data included in the inventory: } \\
\text { price, date of entry of material, date of } \\
\text { output if material, department }\end{array}$ & lack of knowledge on mercury elimination issue \\
\hline Distribution & $\begin{array}{l}\text { distribution of the maximum amount of } \\
\text { allowed stock every } 48 \text { hours }\end{array}$ & $\begin{array}{l}\text { lack of control in the distribution } \\
\text { lack of control of broken thermometers } \\
\text { lack of knowledge on mercury elimination issue }\end{array}$ \\
\hline Use & $\begin{array}{l}\text { acceptance of digital thermometers, no } \\
\text { resistance to change }\end{array}$ & $\begin{array}{l}\text { lack of standardized mercury spills cleaning procedures } \\
\text { lack of knowledge on mercury elimination issue }\end{array}$ \\
\hline Final disposal & & $\begin{array}{l}\text { lack of temporary hazardous waste storage } \\
\text { lack of final disposal of mercury } \\
\text { lack of knowledge on mercury elimination issue }\end{array}$ \\
\hline
\end{tabular}

In developing countries, healthcare systems must allot significant financial and human resources, and training for implementing mercury phase-out programs. Department Memorandum 2011-145 Guidelines for the Temporary Storage of Mercury Wastes in Healthcare Facilities in Accordance to Administrative Order No. 0021 s. 2008 on the Gradual Phase-out of Mercury in all Philippine Health Care Facilities and Institutions states that part of the hospital maintenance and other operating expenses (MOOE) in DOH-retained hospitals should cover the cost of such phase-out programs. If governments are unable to cover for this, several stakeholders may be engaged to make the phase-out more sustainable. Formal partnerships with NonGovernment Organizations (NGOs) and other national government agencies with experience in handling mercury can facilitate the transfer of technology and knowledge to the hospitals. In the USA, the Environmental Protection Agency (EPA), American Hospital Association (AHA), Healthcare Without Harm, and American Nurses Association (ANA) formed the Hospitals for a Healthy Environment to pursue mercury elimination. ${ }^{13}$

When AO 2008-21 was crafted, DOH and hospital implementers worked on the assumption that the mercury wastes will be given to DENR to develop and/or accredit a TSD facility for final disposal. However, as stated in several occasions by the Environmental Management Bureau (EMB) during the 2012 NIH Roundtable Discussion and the 2014 First Consultative Meeting for an administrative order focused on dental amalgams, EMB is strictly a regulatory body. ${ }^{14,15}$ The development and accreditation of TSD facilities for mercury wastes were beyond their jurisdiction. Such predicament is also based on the Joint Administrative Order (JAO) 2005-002 to develop a TSD facility for mercury wastes. If there are conflicting interpretations between the two departments regarding JAO 2005-002, then the JAO must be revised to draw clearer boundaries on what is to be expected between the parties.

Budgetary constraints are a major factor to the delayed implementation of AO 2008-21 by hospitals. ${ }^{16}$ Another fundamental issue to tackle is the low prioritization of Environmental and Occupational Health by DOH. The budget for Environmental and Occupational Health in 2014 is Php53.421 million. The fund will support programs related to water and sanitation, food safety, climate change, solid waste management, chemical safety, occupational health, air quality, and healthcare waste management on a national level. If this is compared to a recently transferred program, Foodborne and Waterborne Diseases, with a budget $\mathrm{PhP} 47.685$ million, a disparity can be observed. Moreover, mercury phase-out is not part of the National Objectives for Health (NOH). ${ }^{16}$ Hence, funding for the phase-out of mercury is not prioritized as compared to other health-related programs.

A similar lack of prioritization has been observed by KIs for hospital management. A hospital administrator must be convinced that mercury phase-out programs should be allotted monetary support in the MOOE. A list of "Benefits of a Mercury Pollution Prevention Program in Your Hospital" may be adapted locally and communicated to administrators to gain support. ${ }^{13}$ Similar programs would also provide quick response procedures, especially during events such as the 2013 mercury oil spill, wherein the disruption of hospital services, higher clean-up costs, and other issues can be addressed. Among the provisions that may be highlighted is the increase in cost-efficiency for hospital operations. Other benefits include: 
1. lower waste disposal costs,

2. reduction of liability for contaminated site remediation,

3. lower operational and maintenance costs,

4. lower risk for public, staff and the environment, and

5. reduction or elimination of environmental health concerns for patients, staff and general public.

Due to the low-resource settings, implementers improvised, for example, on the kind of containers used for storage. Upon reviewing the UNEP guidelines, if the Philippines opt for final disposal of salt mine abroad, there will be a need to procure standardized and compact containers for transport. The old containers will be considered as additional contaminated materials. The re-opening of sealed containers also poses a potential for mercury spills as well.

\section{Implement final disposal of mercury wastes stored in hospitals}

The only solution identified by most of the key informants is the implementation of a final disposal facility. There are three options to be considered: aboveground, underground, and exportation. From the estimates conducted by BanToxics!, exporting mercury wastes is the least expensive compared to the capital outlay and operating costs for above-ground and underground storage facilities. ${ }^{17}$ However, uncertainties on the actual amount of mercury wastes in the Philippine hospitals (due to a lack of inventories) can also prove prohibitive in terms of costs. It is also an administrative nightmare since the country is responsible for collecting all these wastes from each hospital for transfer into standardized containers for transport.

Addressing the aforementioned factors may be through various policies to be pursued at the national and local level. One is the creation of a monitoring system to check the adherence of hospitals to AO 2008-21. Funding and logistic support may be through the Health Facilities Enhancement Program or the Sin Tax. Support for training and advocacy, especially in the local hospitals, may be through cooperation with the local chief executives.

The current burden of disease studies from mercury poisoning will put the appropriate context to the mercury problem in the Philippine healthcare setting. Prevalence studies in the general population and among high-risk occupational groups should be established. Cost-of-illness and Disability-Adjusted Life Years (DALYs) studies maybe helpful.

Studies on cost-effectiveness for the various available long-term storage/final disposal options will be of significant value for policy makers. The only solution thought of by seven out of the ten KIs is the removal of the mercury stores and its final disposal using whatever means. Several KIs, especially after the aforementioned mercury spill incident, have realized the risks imposed by mercury-containing devices: "Dapat talaga alisin na ito dito sa amin, kasi pwede pa ring mag-spill" (We really need to remove this [mercury] in our midst because a spillage could occur).

\section{CONCLUSIONS}

A total amount of $213.5 \mathrm{~kg}$ of mercury-containing devices was documented in $10 \mathrm{DOH}$-retained hospitals in NCR. This volume of mercury-related waste prompts a need to improve the technical knowledge of implementers involved in the mercury phase-out in hospitals. Additionally, systems should be in place to augment the adherence of hospitals to AO 2008-21 and DM 2011-145. Hospitals need support to properly implement mercury phaseout, particularly on training, proper record-keeping, and monitoring of temporary storage. Disposing mercurycontaining devices away from hospital premises is seen as a vital step towards the elimination of mercury exposure in hospitals.

The strengths identified by the Key Informants were the following: 1) hospitals performed one-time collection of mercury-containing devices; 2) mercury-free alternative vendors and NGOs were engaged to provide adequate maintenance services after the purchase of such alternatives; and 3) hospitals demonstrated the accuracy of non-mercury alternatives to convince their end-users.

Based on the findings, the following are the recommendations: 1) Improve information dissemination of issuances to hospitals by cooperating with NGOs; 2) Design a standardized training program with LGUs, including audiovisual guides for frontline level (ward staff and janitorial services), middle-level management (Mercury Management Team/HEMS) and high-level management (hospital managers/administrator) for dissemination; 3) Set-up a monitoring system to ensure that the hospitals adhere to the standards set by AO 21;4) Review and revise current policies with DENR; and 5) Pursue final disposal with possible funding through the Sin Tax or through HFEP.

\section{Acknowledgement}

Sincerest gratitude to the following: Dr. Rodolfo Albornoz of the Department of Health and Dr. Hilton Lam of UPM-NIH for the guidance for this paper. Funding for this study was provided by the DOH Health Policy Development and Planning Bureau and the Philippine Council for Health Research and Development.

\section{Statement of Authorship}

The author approved the final version submitted.

\section{Author Disclosure}

The author declared no conflicts of interest.

\section{Funding Source}

This paper was funded by the DOH Health Policy Development and Planning Bureau and the Philippine Council for Health Research and Development. 


\section{REFERENCES}

1. World Health Organization. International Programme on Chemical Safety. Exposure to Mercury: A Major Public Health Concern [Online]. 2013 [cited 2013 Oct]. Available: http://www.who.int/ipcs/ features/mercury.pdf?ua $=1$

2. US Environmental Protection Agency. Persistent, Bioaccumulative andToxic (PBT) Chemical Program: Fact Sheet [Online]. [cited 2013 Oct] Available: http://www.epa.gov/pbt/pubs/fact.htm

3. Kim K-H, Kabir E, Jahan, SA. A review on the distribution of $\mathrm{Hg}$ in the environment and its human health impacts. Journal of Hazardous Materials 2015;306: 376-385.

4. Ha E, Basu N, Bose-O'Reilly S, Dorea JG, McSorley E, Sakamoto M, Chan HM . Current progress on understanding the impact of mercury on human health. Environmental Research 2016;152: 419-33.

5. World Health Organization. WHO/SDE/WSH/05.08Mercury in Health Care [Online]. 2005. [cited 2013 Nov]. Available: http://www.who.int/water_sanitation_health/_ medicalwaste/ mercurypolpap230506.pdf

6. 67th World Health Assembly. Public Health Impacts of Exposure to Mercury and Mercury Compounds: The Role of WHO and Ministries of Public Health in the implementation of the Minamata Convention [Online]. 2014 [cited 2014 May]. Available: http://apps.who.int/gb/ ebwha/pdf_files/WHA67/A67_R11-en.pdf?ua=1

7. Mercury Assessment for the Philippines using the UNEP Inventory Toolkit [Online]. 2008 [cited 2014 Nov]. Available: https:// wedocs.unep.org/bitstream/handle/20.500.11822/9847/-Mercury_ Inventory_Assessment_for_the_Philippines-2008Philippines_ HgInventoryReport_2008.pdf.pdf?sequence=3\&isAllowed=y

8. Department of Environment and Natural Resources and Department of Health. Joint Administrative Order 2005-02 - Policies and guidelines on effective and proper handling, collection, transport, treatment, storage and disposal of health care waste [Online]. 2005 [cited 2013 Nov]Available: http://pcij.org/blog/wp-docs/joint_denr_doh_AO_2. pdf.
9. Office of the Secretary Department of Health. DOH Administrative Order Number 21 Series of 2008 - Gradual Phase-out of Mercury in all Philippine Health Care Facilities and Institutions [Online]. 2008 cited 2013 Sept]. Available: http://www.cldh.org/dohao212008.html

10. Basel Convention. Overview [Online]. 2011 [cited 2013 Nov]. Available: http://www.basel.int/TheConvention/Overview/tabid/1271/ Default.aspx.

11. Ferrer M. Mercury phase-out examples from Philippine hospitals. Health Care Without Harm Southeast Asia. Powerpoint presentation; 2010; Philippine Heart Center

12. Burgos-Hernandez M. Strategy for mercury elimination in public hospitals of Sonora State, Mexico: Implementation of two research projects for the achievement of a collaborative agreement. ProQuest: University of Massachusetts Lowell, 2009.

13. US Army Public Health Command. Mercury Waste Virtual Elimination Model Plan [Online]. 2010 [cited 2014 May]. Available: https://phc.amedd.army.mil/PHC\%20Resource\%20Library/Final\%20 Hospital\%20Mercury\%20Reduction\%20\%20Plan\%2021\%20Oct\%20 2010\%20agg.pdf

14. Juban N, Panganiban L, Rivera A, et al. Policy Recommendations on the Dental Amalgam. University of the Philippines - National Institutes of Health; 2012 (Unpublished report)

15. Inter-Agency Committee on Environmental Health. First Consultative Meeting on the AO for Dental Amalgam. Department of Health; 2014 (Unpublished report)

16. Department of Health. National Objectives for Health 2011-2016 [Online]. 2012 [cited 2014 May] Available:http://www.doh.gov.ph/ sites/default/files/publications/noh2016.pdf

17. Gutierrez R. BanToxics!. Terminal Storage Waste Options for Mercury Wastes in the Philippines [Online]. 2009 [cited 2014 May] Available: http://www.takagifund.org/e/archives/08/documents/Terminal Storage_Option_mercury_2009.pdf

\section{The Acta Medica Philippina is now accepting limited advertising for its front and back cover (colored), as well as for available spaces in some of its pages, as appropriate. For inquiries and submission of proposals, please e-mail us at actamedicaphilippina@yahoo.com}

